\title{
OSTEOPOROSIS AND PERIODONTAL DISEASE: ASSOCIATION AND MECHANISMS: AN IN-DEPTH REVIEW
}

\author{
Ruparani Bodduru ${ }^{1}$, Khushbu Deshmukh ${ }^{1}$, SnehalChandraprakash Chintawa ${ }^{1}$, Abhishek \\ Singh Nayyar ${ }^{2} *$ \\ ${ }^{1}$ Department of Periodontics, Saraswati-Dhanwantari Dental College and Hospital and Post-Graduate \\ Research Institute, Parbhani, Maharashtra \\ ${ }^{2}$ Department of Oral Medicine and Radiology, Saraswati-Dhanwantari Dental College and Hospital and Post- \\ Graduate Research Institute, Parbhani, Maharashtra, India.
}

\begin{abstract}
Systemic bone loss has been proposed as a risk factor for periodontal disease with increasing evidences that osteoporosis and the underlying loss of bone mass characteristic of this disease is associated with periodontal disease and tooth loss. Periodontal disease is a microbial infection, but the exact etiology of the disease may be multi-factorial. Risk factors associated with periodontal disease include accumulation of dental plaque and host-response abnormalities, involving smoking and many systemic diseases like diabetes, respiratory diseases, cardiovascular diseases, adverse pregnancy outcome and osteoporosis.
\end{abstract}

Keywords: Osteoporosis, periodontal disease, risk factors

\section{INTRODUCTION}

Periodontal disease and osteoporosis are multifactorial in their etiology and involve a large strata of the population in India and all over the world. Osteoporosis is a systemic skeletal disease characterized by low bone mass and microarchitectural deterioration of the bone scaffold that results in increased bone fragility and susceptibility to fractures. ${ }^{1}$ In osteoporosis, the bone mineral density (BMD) is reduced, bone micro-architecture is disrupted and the amount and variety of non-collagenous proteins in bone is altered ${ }^{2}$ while, periodontitis is an inflammation of the supporting tissues of the teeth, usually leading to loss of bone and periodontal ligament and is a major cause of tooth loss and edentulousness in adults $^{3}$.Systemic loss of bone density in osteoporosis including that of the jaw may provide a host system that is increasingly susceptible to infectious destruction of periodontal tissues. ${ }^{4}$ Loss of alveolar bone is a prominent feature of periodontal disease while severe osteoporosis could be suspected of being an aggravating factor in cases of excessive periodontal destruction. It has been hypothesized that the breakdown of periodontal tissue may, in part, be related to systemic conditions that also predispose the patient to osteoporosis/osteopenia. ${ }^{5}$

*Corresponding author:

Email: singhabhishek.rims@gmail.com

http://dx.doi.org/10.20530/IJTA $32 \quad 11-19$

ISSN 2320-138X C) 2016
Osteoporosis: Classification: Osteoporosis means literally "porous bone", a condition, where there is "too little bone" to provide mechanical support. Osteoporosis was once thought to be a part of a natural aging process in women. Today, it is not considered to be age dependent or gender specific. ${ }^{6}$ Osteoporosis is defined as a skeletal disorder characterized by compromised bone strength predisposing an individual to an increased risk of fractures. ${ }^{7}$ Bone strength primarily reflects the integration of bone density and bone quality.Bone density is expressed as grams of mineral per unit area or volume, and in any given individual, is determined by peak bone mass and amount of bone loss.Bone quality refers to architecture, turnover, damage accumulations (e.g.microfractures) and mineralization.The standard deviation is determined by certain established criteria namely:T-score which is defined as the number of standard deviations above or below the average bone mineral density (BMD) value for young healthy white women and Z-score which is defined as the number of standard deviations above or below the average BMD for age and sex matched controls.

Following classification is based on standard deviation:

The various methods for assessing bone are as follows ${ }^{9,10}$ :

A) Systemic bone:

a) Absorptiometry

- Single photon absorptiometry

- Dual photon absorptiometry

b) Dual Energy X-Ray Absorptiometry (DEXA) 


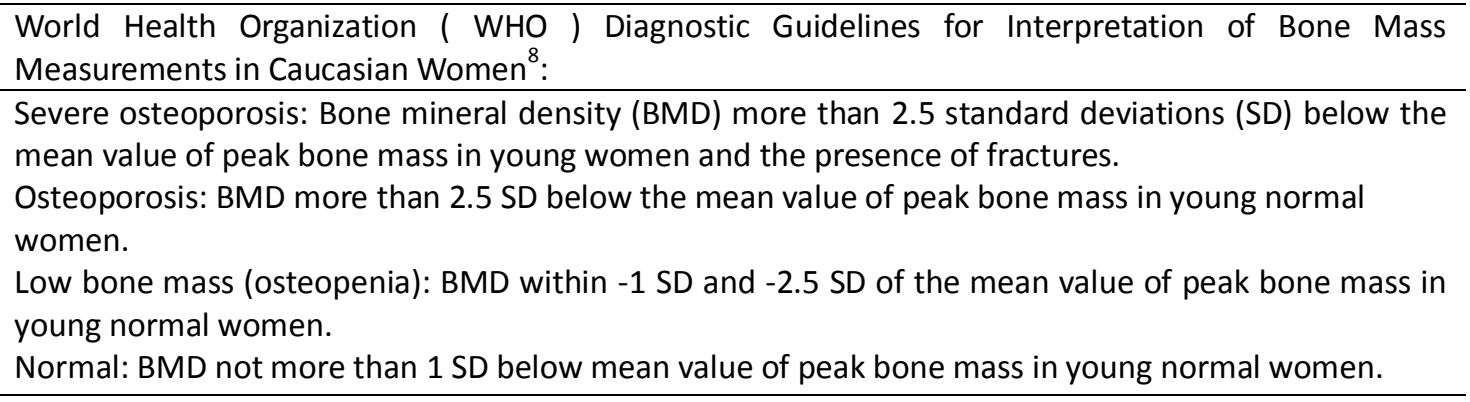

c) Quantitative Computed Tomography (QCT)

d) Measurement from radiographs

- Measurement of cortical thickness and other indices

- Fractal dimension

e) Ultrasound

B) Intra-oral Sites (Research tools):

a) Adaptation of absorptiometry or DEXA

b) Measurement from panoramic films

c) Cortical thickness and other indices

d) Measurement from intra-oral films

e) Measurement of bone or ridge height

f) Apparent bone density expressed as arbitrary units based on the reference wedge

g) Digital subtraction radiography (changes in bone height $(\mathrm{mm})$ or density $\left(\mathrm{mg} / \mathrm{mm}^{2}\right)$

h) Fractal dimension

i) Microdensitometry

j) Pixel intensity analysis

Co-risk factors for osteoporosis and periodontal disease:Osteoporosis and periodontal disease share common risk factors. Prevalence of both osteoporosis and tooth loss increase with advancing age in women. Risk factors for osteoporosis can be divided into non-modifiable and modifiable risk factors. The non-modifiable risk factors for osteoporosis include gender, age, early menopause, small body frame, race and heredity while lack of calcium and vitamin D, lack of exercise, smoking and alcohol consumption are modifiable risk factors. In addition, there are other risk factors such as diabetes, diet and hormone levels that affect systemic bone level and may also affect periodontitis. ${ }^{11}$ While the pathogenesis of osteoporosis and periodontitis differ, these diseases, are thought to share several common risk factors as depicted below.

Risk factors for Osteoporosis and Periodontal Diseases $^{12,13}$ :

Osteoporosis-Prevention Strategies: It is important to identify the risk factors for individual patients and develop preventive strategies for them. There are general principles and recommendations for prevention formulated by the National Osteoporosis Foundation.

1. All women should be counselled on the risk factors.

2. An evaluation of bone mineral density should be performed on all post-menopausal women who present with fractures to determine the diagnosis and disease severity.

3. Bone mineral density testing is recommended for all post-menopausal women younger than 65 years, who have one or more risk factors for osteoporosis in addition to menopause.

4. Bone mineral density testing is recommended for all women 65 years and older regardless of additional risk factors.

5. All diagnosed patients are counselled to obtain an adequate dietary intake of calcium.

6. Regular weight bearing and muscle strengthening exercises to reduce the risk of falls and fractures are recommended.

7. Patients should be advised against smoking and smoking cessation should be implemented.

8. Alcohol intake should be at a moderate level (about one drink per day for women and two drinks per day for men).

9. All post-menopausal women who present with hip fractures or vertebral fractures should be considered candidates for osteoporosis treatment.

Pharmacological options for osteoporosis prevention and treatment include Hormone Replacement Therapy (HRT), alendronate, and raloxifene for prevention and calcitonin for treatment. ${ }^{14}$ Clinicians, including dentists, should inform and motivate the public to make and sustain life style changes relating to exercise, diet, tobacco, and alcohol use.The National Osteoporosis Foundation as well as the National Academy of Sciences recommends a daily intake of $1200 \mathrm{mgs}$ of dietary calcium and 400-800IU of vitamin D.Tobacco use should be discouraged and current smokers should be encouraged to quit on their own or participate in smoking cessation programmes. Counselling and treatment should be offered to patients with excessive alcohol 


\begin{tabular}{lll}
\hline & Osteoporosis & Periodontal disease \\
\hline Hereditary/genetics & Female gender & Age \\
& Caucasian/ Asian race & Race \\
& Family history & Familial aggregation \\
& Menopause & IL-1 polymorphism \\
& Petite body build & \\
& Suboptimal peak bone & \\
Dietary factors & Low intake of calcium & Low intake of Calcium \\
& Low intake of vitamin D & Low intake of vitamins C, A, selenium \\
& High intake of caffeine, protein,, & \\
Environment & salt, phosphate & \\
& Smoking & Smoking \\
& Alcohol & Alcohol \\
Systemic factors & Physical inactivity & Stress \\
& Diabetes mellitus & Diabetes mellitus \\
& Multiple myeloma & Osteoporosis \\
& Connective tissue diseases & Hormonal changes \\
\hline
\end{tabular}

consumption as part of the life style modifications to prevent osteoporosis. ${ }^{15}$ The beneficial effects of physical activity and weight bearing exercises have been well documented. ${ }^{16-18}$

Chemotherapeutic agents for treatment of osteoporosis and oral bone loss: Several pharmacological agents are available to increase bone mineral density and therefore treat or prevent osteoporosis. They include Hormone Replacement Therapy (HRT), bisphosphonates, calcitonin, selective estrogen receptor modulators, parathyroid hormone or combination of these agents.There is sufficient evidence in the literature to demonstrate that depending on the drug and the patient population, treatment reduces the risk of vertebral fractures by $30-65 \%$ and non-vertebral fractures by $46-53 \%{ }^{19}$

Hormone Replacement Therapy (HRT):Rapid loss of bone density is observed because of estrogen deficiency in the early post-menopausal years. The rationale for HRT is to delay this bone loss. Estrogen therapy can inhibit osteoclast formation and function and can also extend the lifespan of osteoblasts and osteocytes. ${ }^{20}$ In a randomized clinical trial, as part of the women's health initiative trial, women were randomly assigned to receive conjugated estrogens, with or without a progestin and the reduction in hip fractures was reported to be $33 \%$. HRT increased total hip bone density and reduced the risk of fractures at the hip, vertebrae and wrist. ${ }^{21}$ Also, discontinuation of estrogen results in measurable bone loss, although it is not certain whether discontinuation results in a greater fracture risk than continuation. ${ }^{22}$ Recently, concern has been raised about the non-skeletal risks associated with long term use of estrogen. Evidence of an increased risk of breast cancer and of cardiovascular outcomes during the course of the estrogen plus progestin trial of the women's health initiative prompted early termination of this trial in $2002 .{ }^{21}$ This has led to a re-evaluation of the role of HRT in the treatment and prevention of osteoporosis. HRT should not be recommended for prevention of osteoporosis in post-menopausal women, unless they are found to be at a significant risk for osteoporosis, and other osteoporosis medications are unable to be considered..$^{23}$ It is, therefore, important that women discontinuing HRT receive appropriate screening for their risk for complications of osteoporosis and should be counselled regarding the alternative forms of therapy to prevent fractures. ${ }^{24}$

Selective estrogen receptor modulators: Selective estrogen receptor modulators were developed to provide the benefits of estrogen therapy without its unwanted side effects. Their mechanism of action such as that of raloxifene is similar to that of the estrogens. ${ }^{25}$ Reduction in fractures was observed in the first year of treatment but no effect was found on the risk of non-vertebral fractures. Adverse effects included hot flashes and cramps. Similar to estrogen therapy, an increase in the incidence of deep vein thrombosis was also observed with these agents. ${ }^{26} \mathrm{New}$ selective estrogen-receptor modulators are being researched and may be available in the near future.

Bisphosphonates:Bisphosphonates are analogues of pyrophosphonates and bind selectively to bone mineral. During bone resorption, they are taken-up by the osteoclasts, resulting in osteoclast deactivation and apoptosis. Bone resorption is suppressed followed by a secondary mineralization 
resulting in increased bone mass, improving bone strength and a reduction in fractures. ${ }^{27}$ Bisphosphonates are often considered the first-line therapy for the treatment of post-menopausal osteoporosis. They are the most widely prescribed anti-resorptive agents. Randomized trials of alendronate and risedronate, two second generation bisphosphonates demonstrated increased bone mineral density in postmenopausal women with osteopenia or osteoporosis. In women with osteoporosis, a reduction in the incidence of hip, vertebral and non-vertebral fractures of nearly $50 \%$ was found. This effect was noted early in therapy. ${ }^{28-31}$ However, the occurrence of osteonecrosis of the jaws with the use of intravenous bisphosphonates is of concern to the dental community. After initial observations by Wang at the University of California,osteonecrosis of the jaws is seen to occur more commonly in the mandible but has also been reported in the maxilla, and appears to be highly associated with periodontitis, other oral infections, and extraction of the affected teeth in majority of the reported cases. ${ }^{32}$ In addition, the signs and symptoms that may occur before the appearance of clinically evident osteonecrosis include changes in the health of the periodontal tissues, non-healing mucosal ulcers, and unexplained soft tissue infections. The role of oral bisphosphonates in osteonecrosis of the jaws, therefore, needs to be further evaluated.

Calcitonin: Calcitonin is an inhibitor of osteoclast activity. Both nasal and subcutaneous calcitonin are available for treatment of post-menopausal osteoporosis. Treatment of women with osteoporosis with nasal calcitonin has been shown to reduce the incidence of vertebral fractures by $33 \%$ when compared to placebo in a randomized controlled trial. ${ }^{33}$

Osteoporosis and oral bone loss: Periodontitis, a major cause of tooth loss, is clinically determined by radiographic bone loss and/or clinical attachment loss (CAL). Although bacterial plaque is the primary cause of periodontitis, host susceptibility or responsiveness is believed to play a major role in the initiation and progression of tissue destruction. Both osteoporosis and periodontitis are bone-resorptive, host-dependent, multifactorial diseases, and the bone loss in both diseases is exaggerated, either systemically or locally, by the activity of cytokines (e.g., IL-1 and IL$6)$. In 1973, the association between periodontal disease and osteoporosis was studied. Metacarpal bone index was used for grading the degree of osteoporosis. Periodontal parameters measured were gingival and periodontal index which were carried-out in 113 patients with a mean age of 35 years. This study concluded that people with lower metacarpal indices had more severe periodontal disease than those with higher metacarpal index. ${ }^{34}$ Another case control study carried-out with 12 osteoporotic women and 14 in the control group with both groups having dentulous patients determined the BMD with dual photon scanner of two forearms and the mandible. Plaque, bleeding scores and loss of attachment were measured. It was found that greater loss of attachment occurred in osteoporotic women. ${ }^{35}$ Advanced periodontal disease was measured using Community periodontal index of treatment needs and bone support was calculated on panoramic radiographs as bone support both mesially and distally as the length of root with normal width of periodontal ligament space and divided by total length of root from cemento-enamel junction to the apex of root. Bone mineral density of femoral neck and lumbar spine was assessed using dualenergy X-ray absorptiometry. The BMD of mandibular cortex was measured both labially and lingually between the mental foramens using quantitative computed tomography (QCT). This study came to an important conclusion that even if initiation of periodontal disease is not dependent on the general mineral status of the body, individuals who have high mineral values in the skeleton seem to retain their teeth with deep periodontal pockets easier than those with osteoporosis. ${ }^{36}$ Another case control study investigated the strength of association between periodontal disease and spinal bone density. Assessment of periodontal disease was done by assessing the pocket depth, gingival recession, gingival index, plaque index and periodontal attachment levels. Spinal bone mineral density was measured by DEXA .There was significantly greater level of attachment loss found in osteoporotic group compared to controls. The conclusion of the study was that osteoporosis may contribute to periodontal attachment loss, though pocket depths were not deeper and osteoporotic subjects had greater gingival recession compared to controls. ${ }^{37} \mathrm{~A}$ three year old longitudinal study was undertaken to assess the relation of postmenopausal bone loss after menopause to periodontal attachment apparatus, and if estrogen therapy mitigates both post-menopausal bone loss and loss of attachment apparatus. Clinical measures of body size, body mass index, and smoking history in terms of pack years, menopausal history including age at menarche, menstrual irregularities, years of use of birth control medications and years since menopause were assessed. Oral findings including attachment 
loss, number of teeth present, probing depth and recession was recorded for the whole mouth. Bone mineral density (vertebral and proximal femur) was measured using dual energy X-ray absorptiometry. The study summarized that post-menopausal age and smoking were relevant factors contributing to loss of periodontal attachment. ${ }^{38}$ Study of estrogen status has assumed a major part in association with osteoporosis since estrogen levels are lower in post-menopausal women in whom the incidence of osteoporosis is higher. A case control, prospective, longitudinal study was carried-out on 70 post-menopausal women. Here, women were divided into estrogen deficient and estrogen sufficient groups after assessing serum 17estradiol levels. DEXA was used to measure BMD in periodontitis patients. Periodontal measures recorded were 4 posterior interproximal sites in periodontitis patients and in non-periodontitis patients' plaque index, bleeding index, probing depth and relative clinical attachment levels. It was concluded that estrogen supplementation may lower gingival inflammation and rate of clinical attachment loss in osteopenic/osteoporotic population. ${ }^{39}$ Weyant et al studied a cross-section of a large sample of osteoporotic women in the postmenopausal age. The average age of participants was 70.7 years and BMD was measured using single photon absorptiometry at the hip, spine, radius and calcaneus regions. The oral variables assessed were missing teeth, bleeding index, calculus indexand periodontal assesment consisting of probing pocket depth and loss of clinical attachment. This study found no association between systemic osteopenia and increased risk for periodontal disease. ${ }^{40}$ Effect of estrogen replacement therapy was studied as a modifier of association of periodontal disease and BMD in addition to studying the association between skeletal BMD and periodontal disease. The participants consisted of both edentulous and dentate individuals. Periodontal examination included probing depth, clinical attachment level, calculus and bleeding index. DEXA scan was used to assess BMD of proximal femur. The study indicated, in the presence of high levels of calculus, individuals with osteoporosis and to a lesser extent those with osteopenia, present significantly more attachment loss than individuals with normal BMD. The negative (i.e. protective) association between reported use of estrogen replacement therapy and periodontal disease also suggests that estrogen supplementation may decrease the risk of periodontal disease in women. ${ }^{41}$ The association of systemic bone loss with alveolar bone loss and periodontal disease was assessed in yet another cross-sectional study on Caucasian women in the post-menopausal age. Here, DEXA scan was the method of assessing bone mineral density of lumbar spine and femur. Complete head and neck examination along with the intra-oral periodontal parameters of plaque, calculus, bleeding and clinical attachment loss was carried-out. Alveolar bone loss was assessed using the method of Hausmann`susing both bite-wing and peri-apical radiographs. Smoking history in terms of pack years was an additional parameter which was taken into account. The results of the study suggested that systemic bone loss is related to alveolar bone loss, and to a lesser extent to clinical attachment loss.The relation of alveolar bone loss suggests that osteoporosis may play an indirect role on periodontal disease. ${ }^{42} \mathrm{~A}$ deviation from the normal was a study to assess whether mandibular and skeletal bone mineral content or density are related and the bone differed from normal values in a set of young patients. The markers for bone resorption i.e. alkaline phosphatase, pyridinoline, deoxypyridinoline were measured. Normal periodontal parameters with alveolar bone loss were examined. This study concluded that severe periodontitis in young adults is a local disorder associated with a relatively low BMC in jaws without systemic alterations of BMD and bone metabolism. ${ }^{43}$ The prevalence of osteopenia/osteoporosis as defined by self report was studied in an ethnically diverse population. Additionally the extent of relation of cortical bone changes on panoramic radiographs to this report and finally, the association of osteoporosis with periodontitis was evaluated. The inference of the study was that prevalence of signs of osteoporosis using mandibular cortical index on panoramic radiographs is high though it is low with the self reported history.There was a clear association of osteoporosis with periodontitis. ${ }^{44}$ Healthy postmenopausal women were recruited for studying relation between BMD of lumbar spine, proximal femur and periodontal attachment level. Periodontal findings of probing depth and recession were noted. DEXA was used for BMD of skeletal bones. There was a very weak correlation at the end of 3 years between BMD of skeleton and clinical attachment level. ${ }^{45} \mathrm{~A}$ longitudinal study was conducted on a community of older individuals to evaluate the relation between systemic BMD and periodontal disease. BMD was measured using an ultrasound densitometer of the heel. The study concluded that a significant association existed between periodontal disease and general BMD. ${ }^{46}$ Osteoporotic and normal subjects were compared with respect to periodontitis in a group of 50 subjects. In addition to plaque index, calculus index, periodontal index, 
gingival index, bleeding index, even concremente index was taken. Osteoporosis was diagnosed based on absolute and T-scores and most of the subjects included were post-menopausal females. It was concluded that osteoporotic people have higher incidence of tooth loss. The clinical parameters were however not found to be significantly different in between the groups. ${ }^{47}$ In summary, although the causality between systemic bone loss and oral bone loss has not been determined, the evidence demonstrates a plausible association between the two disease entities. Study results imply that individuals with either systemic or oral bone loss should be closely managed with a clinical protocol that minimizes further deterioration of systemic or oral bony structures. Additional randomized, controlled clinical trials are needed to clarify the causality and/or association between systemic and oral bone loss.

Mechanism of association between osteoporosis and periodontitis:Mechanisms by which osteoporosis or systemic bone loss may be associated with periodontal attachment loss, loss of alveolar bone height and tooth loss continue to be explored.First, low bone mineral density in the oral bone may be associated with low systemic bone. This low bone density or loss of bone mineral density may lead to a rapid resorption of alveolar bone along with periodontal disease caused by periodontal bacteria as it intensifies the bone loss.Second, systemic factors affecting bone remodeling may also modify local tissue response to periodontal infections. Individuals with systemic bone loss are known to have increased systemic production of cytokines (i.e. interleukin-1 and interleukin-6) that may have an effect on bone throughout the body, including the bones of oral cavity. Periodontal infection has been shown to increase the local cytokine production that, in turn, increases local osteoclast activity resulting in increased bone resorption.Third, genetic factors that predispose a person to systemic bone loss also influence or predispose a person to periodontal destruction.Lastly, certain lifestyle factors such as cigarette smoking and suboptimal calcium intake, amongst others, may put individuals at risk for development of both osteopenia and periodontal disease. ${ }^{42}$ It has been hypothesized that osteoporosis may cause decreased alveolar bone density, which in turn, may be more susceptible to resorption by the effect of co-existing or subsequent periodontal infection and inflammation. ${ }^{48}$

Implications for treatment of patients with osteoporosis and periodontitis: Medications and strategies in current use for osteoporosis prevention and treatment include bisphosphonates, selective estrogen receptor modulators (SERMs), calcitonin, hormone replacement therapy (HRT) and nutritional supplementsof calcium andvitamin D.

Anti-resorptive medications: These groups of medications act on resorption phase without affecting the formation in osteoporosis. The bisphoshonates have been shown to prevent alveolar resorption and preserve mandibular bone mass in animals, but their exact role has not been clearly established in human studies.Also, the retention of teeth has been reported to be higher in patients on $\mathrm{HRT}^{41}$

Effects of dietary calcium and vitamin D have been widely studied. Nishida et al surveyed the dietary intake of calcium and periodontal examination on 12,000 adults. It was found that there was inverse association between dietary calcium intake and level of periodontal disease, controlling for smoking and age. The prevalence of periodontal disease was $30 \%$ to $60 \%$ higher, depending on gender, in individuals with calcium intake below $800 \mathrm{mgs}$ compared to those with calcium intake above $88 \mathrm{mgs}$. While this data supports a link between low dietary calcium and higher prevalence of periodontal disease, limitations of the study included the lack of information on the contribution of calcium supplements to total calcium intake and the crosssectional design. ${ }^{49}$ Again, a study by Richard A etal concluded that estrogen supplementation may lower gingival inflammation and rate of clinical attachment loss in osteopenic/osteoporotic population. $^{39}$

Future research: Currently marketed osteoporosis therapies including bisphosphonates and selective estrogen modulators are efficacious but inconvenient for the patients because of the need for frequent administration and the risk of adverse effects. The active immunization strategy against TRANCE/RANKL using C-TRANCE-VLPs may offer a safe, efficient and cost-effective new therapeutic option for the treatment of osteoporosis. $^{50}$

\section{CONCLUSION}

The effects of osteoporosis on both systemic health and oral health need to be well understood. As a health care provider, the dentist could serve as a pre-screener of patients with the potential for osteopenia or osteoporosis. Familiarity with the risk factors could help identify these individuals and aid in an earlier diagnosis and immediate 
treatment required.

\section{REFERENCES}

1. NIH Consensus Development Panel on Osteoporosis Prevention, Diagnosis, and Therapy. Osteoporosis Prevention, Diagnosis, and Therapy. JAMA: The Journal of the American Medical Association. 2001 Feb 14;285(6):785-95. Available from: http://dx.doi.org/10.1001/jama.285.6.785.

2. Willaim V Giannobile, Hectro F Rios, Niklaus P Lang. In: Bone as a tissue, Clinical periodontology and implant dentistry Jan Lindhe, Niklaus $P$ Lang, ThorkildKarring. $5^{\text {th }}$ edition $2007 ; 86-94$.

3. American academy of periodontology. Glossary of periodontal terms, $4^{\text {th }}$ edition. Chocago: The American Academy of periodontitis. 2001; 39.

4. Wactawski-Wende J. Periodontal Diseases and Osteoporosis: Association and Mechanisms. Annals of Periodontology. 2001 Dec;6(1):197-208. Available from: http://dx.doi.org/10.1902/annals.2001.6.1.197.

5. Yu-Lin Lai. Osteoporosis and Periodontal Disease. J Chin Med Assoc 2004;67:387-388.

6. Sivaramakrishnan S, Kannan S, Reddy L. Euphytica. 2002;125(1):21-8. Available from: http://dx.doi.org/10.1023/a:1015759318497.

7. NIH Consensus Development Panel on Osteoporosis Prevention, Diagnosis, and Therapy. Osteoporosis Prevention, Diagnosis, and Therapy. JAMA: The Journal of the American Medical Association. 2001 Feb 14;285(6):785-95. Available from: http://dx.doi.org/10.1001/jama.285.6.785.

8. World Health Organization. Assessment of fracture risk and its application to screening for postmenopausal osteoporosis. Technical Report Series. Geneva: WHO. 1994.

9. Wahner HW. Use of densitometry in management of osteoporosis. In:MarcusR,Feldman D, Kelsey J,eds. Osteoporosis San Diego: Academic Press 1996;23:1055-1074.

10. Anna N Law, Anne-Marie Bollen, Ssu-Kuang Chen. Detecting osteoporosis using dental radiographs: A comparison of four methods. JADA 1996;127:17341742.

11. Geurs NC, Lewis CE, Jeffcoat MK. Osteoporosis and periodontal disease progression. Periodontol 2000. 2003 Jun;32(1):105-10. Available from: http://dx.doi.org/10.1046/j.09066713.2003.03208.x

12. Kanis JA, McCloskey EV. Risk factors in osteoporosis. Maturitas. 1998 Nov;30(3):229-33. Available from: http://dx.doi.org/10.1016/s0378-5122(98)00090-5.

13. ROSS PD. RISK FACTORS FOR OSTEOPOROTIC FRACTURE. Endocrinology and Metabolism Clinics of North America. 1998 Jun;27(2):289-301. Available from: http://dx.doi.org/10.1016/s0889-
8529(05)70006-2.

14. National Osteoporosis Foundation. Physicians guide to prevention and treatment of osteoporosis. Washington, DC: The Foundation, 1998:1-2. Foundation TNO, Retrieved from http://www.nof.org (last accessed on 2006Aug)

15. Management of postmenopausal osteoporosis: position statement of The North American Menopause Society. Menopause. 2002 Mar;84101. Available from: http://dx.doi.org/10.1097/00042192-20020300000003.

16. Ernst E. Exercise for Female Osteoporosis. Sports Medicine. 1998;25(6):359-68. Available from: http://dx.doi.org/10.2165/00007256-19982506000002.

17. Feskanich D. Walking and Leisure-Time Activity and Risk of Hip Fracture in Postmenopausal Women. JAMA. 2002 Nov 13;288(18):2300. Available from: http://dx.doi.org/10.1001/jama.288.18.2300.

18. KEMMLER W, ENGELKE K, LAUBER D, WEINECK J, HENSEN J, KALENDER WA. Exercise effects on fitness and bone mineral density in early postmenopausal women: 1-year EFOPS results. Medicine \& Science in Sports \& Exercise. 2002 Dec;34(12):2115-23. Available from: http://dx.doi.org/10.1097/00005768-20021200000038.

19. Delmas PD, Rizzoli R, Cooper C, Reginster J-Y. Treatment of patients with postmenopausal osteoporosis is worthwhile. The position of the International Osteoporosis Foundation. Osteoporos Int. 2004 Nov 23;16(1):1-5. Available from: http://dx.doi.org/10.1007/s00198-004-1813-0.

20. Manolagas SC. Birth and Death of Bone Cells: Basic Regulatory Mechanisms and Implications for the Pathogenesis and Treatment of Osteoporosis 1 . Endocrine Reviews. 2000 Apr;21(2):115-37. Available from: http://dx.doi.org/10.1210/edrv.21.2.0395.

21. Rossouw JE, Anderson GL, Prentice RL, LaCroix AZ, Kooperberg C, Stefanick ML, et al. Writing Group for the Women's Health Initiative I: Risks and benefits of estrogen plus progestin in healthy postmenopausal women: Principal results from the Women's Health Initiative randomized controlled trial. J Am Med Assoc 2002;288:321-333.

22. Cauley JA, Robbins J, Chen Z, Cummings SR, Jackson RD, LaCroix AZ, et al. Women's Health Initiative I: Effects of estrogen plus progestin on risk of fracture and bone mineral density: The Women's Health Initiative randomized trial. J Am Med Assoc 2003;290:1729-1738.

23. Greenspan SL, Resnick NM, Parker RA. Combination Therapy With Hormone Replacement and Alendronate for Prevention of Bone Loss in Elderly Women. JAMA. 2003 May 21;289(19):2525. Available from: 
http://dx.doi.org/10.1001/jama.289.19.2525.

24. Ettinger B, Grady D, Tosteson ANA, Pressman A, Macer JL. Effect of the Women's Health Initiative on Women's Decisions to Discontinue Postmenopausal Hormone Therapy. Obstetrics \& Gynecology. 2003 Dec;102(6):1225-32. Available from: http://dx.doi.org/10.1097/00006250-20031200000005.

25. Barrett-Connor E, Wehren LE, Siris ES, Miller $P$, Chen $Y-T$, Abbott TA, et al. Recency and duration of postmenopausal hormone therapy: effects on bone mineral density and fracture risk in the National Osteoporosis Risk Assessment (NORA) study. Menopause. 2003 Sep;10(5):412-9. Available from: http://dx.doi.org/10.1097/01.gme.0000086467.827 59.da.

26. Wood AJ, Riggs BL, Hartmann LC. Selective Estrogen-Receptor Modulators - Mechanisms of Action and Application to Clinical Practice. N Engl J Med. 2003 Feb 13;348(7):618-29. Available from: http://dx.doi.org/10.1056/nejmra022219.

27. Delmas PD, Ensrud KE, Adachi JD, Harper KD, Sarkar $S$, Gennari C, et al. Efficacy of Raloxifene on Vertebral Fracture Risk Reduction in Postmenopausal Women with Osteoporosis: FourYear Results from a Randomized Clinical Trial. The Journal of Clinical Endocrinology \& Metabolism. 2002 Aug;87(8):3609-17. Available from: http://dx.doi.org/10.1210/jcem.87.8.8750.

28. Reszka AA, Rodan GA. Bisphosphonate mechanism of action. Current Rheumatology Reports. 2003 Jan;5(1):65-74. Available from: http://dx.doi.org/10.1007/s11926-003-0085-6.

29. Black DM, Cummings SR, Karpf DB, Cauley JA, Thompson DE, Nevitt MC, et al. Randomised trial of effect of alendronate on risk of fracture in women with existing vertebral fractures. The Lancet. 1996 Dec;348(9041):1535-41. Available from: http://dx.doi.org/10.1016/s0140-6736(96)07088-2.

30. Ensrud KE, Barrett-Connor EL, Schwartz A, Santora AC, Bauer DC, Suryawanshi S, et al. Randomized Trial of Effect of Alendronate Continuation Versus Discontinuation in Women With Low BMD: Results From the Fracture Intervention Trial Long-Term Extension. Journal of Bone and Mineral Research. 2004 Mar 29;19(8):1259-69. Available from: http://dx.doi.org/10.1359/jbmr.040326.

31. Harris ST. Effects of Risedronate Treatment on Vertebral and Nonvertebral Fractures in Women With Postmenopausal Osteoporosis $<$ SUBTITLE $>$ A Randomized Controlled Trial</SUBTITLE $>$. JAMA. 1999 Oct 13;282(14):1344. Available from: http://dx.doi.org/10.1001/jama.282.14.1344.

32. Wang J, Goodger N., Pogrel M. Osteonecrosis of the jaws associated with cancer chemotherapy. Journal of Oral and Maxillofacial Surgery. 2003 Sep;61(9):1104-7. Available from: http://dx.doi.org/10.1016/s0278-2391(03)00328-8.
33. Chesnut $\mathrm{CH}$, Silverman $\mathrm{S}$, Andriano $\mathrm{K}$, Genant $\mathrm{H}$, Gimona A, Harris $S$, et al. A randomized trial of nasal spray salmon calcitonin in postmenopausal women with established osteoporosis: the prevent recurrence of osteoporotic fractures study. The American Journal of Medicine. 2000 Sep;109(4):267-76. Available from: http://dx.doi.org/10.1016/s0002-9343(00)00490-3.

34. Phillips HB, Ashley FP. The relationship between periodontal disease and a metacarpal bone index. Br Dent J. 1973 Mar 20;134(6):237-9. Available from: http://dx.doi.org/10.1038/sj.bdj.4802984.

35. Wowern $\mathrm{N}$ von, Klausen B, Kollerup G. Osteoporosis: A Risk Factor in Periodontal Disease. Journal of Periodontology. 1994 Dec;65(12):11348. Available from: http://dx.doi.org/10.1902/jop.1994.65.12.1134.

36. Klemetti E, Collin H-L, Forss $\mathrm{H}$, Markkanen $\mathrm{H}$, Lassila V. Mineral status of skeleton and advanced periodontal disease. J Clin Periodontol. 1994 Mar;21(3):184-8. Available from: http://dx.doi.org/10.1111/j.1600-

051x.1994.tb00301.x.

37. Abel Rahim Mohammad, Michael Brunsvold. The strength of association between systemic postmenopausal osteoporosis and periodontal disease.Int J Prosthodont. 1996;9:479-483.

38. Hildebolt CF, Pilgram TK, Dotson M, YokoyamaCrothers N, Muckerman J, Mauser J, et al. Attachment loss with postmenopausal age and smoking. J Periodontal Res. 1997 Oct;32(7):619-25. Available from: http://dx.doi.org/10.1111/j.16000765.1997.tb00940.x.

39. Reinhardt RA, Payne JB, Maze CA, Patil KD, Gallagher SJ, Mattson JS. Influence of Estrogen and Osteopenia/Osteoporosis on Clinical Periodontitis in Postmenopausal Women. Journal of Periodontology. 1999 Aug;70(8):823-8. Available from: http://dx.doi.org/10.1902/jop.1999.70.8.823.

40. Weyant RJ, Pearlstein ME, Churak AP, Forrest K, Famili P, Cauley JA. The Association Between Osteopenia and Periodontal Attachment Loss in Older Women. Journal of Periodontology. 1999 Sep;70(9):982-91. Available from: http://dx.doi.org/10.1902/jop.1999.70.9.982.

41. Ronderos M, Jacobs DR, Himes JH, Pihlstrom BL. Associations of periodontal disease with femoral bone mineral density and estrogen replacement therapy: cross-sectional evaluation of US adults from NHANES III. J Clin Periodontol. 2000 Oct;27(10):778-86. Available from: http://dx.doi.org/10.1034/j.1600051x.2000.027010778.x.

42. Tezal M, Wactawski-Wende J, Grossi SG, Ho AW, Dunford R, Genco RJ. The Relationship Between Bone Mineral Density and Periodontitis in Postmenopausal Women. Journal of Periodontology. 2000 Sep;71(9):1492-8. Available 
from:

http://dx.doi.org/10.1902/jop.2000.71.9.1492.

43. Von Wowern N, Westergaard J, Kollerup G. Bone mineral content and bone metabolism in young adults with severe periodontitis. J Clin Periodontol. 2001 Jun;28(6):583-8. Available from: http://dx.doi.org/10.1034/j.1600-

051x.2001.028006583.x.

44. Persson RE, Hollender LG, Powell LV, MacEntee MI, Wyatt CCL, Kiyak HA, et al. Assessment of periodontal conditions and systemic disease in older subjects. I. Focus on osteoporosis. J Clin Periodontol. 2002 Sep;29(9):796-802. Available from: $\quad$ http://dx.doi.org/10.1034/j.1600051x.2002.290902.x

45. Pilgram TK, Hildebolt CF, Dotson M, Cohen SC, Hauser JF, Kardaris E, et al. Relationships Between Clinical Attachment Level and Spine and Hip Bone Mineral Density: Data From Healthy Postmenopausal Women. Journal of Periodontology. 2002 Mar;73(3):298-301. Available from: http://dx.doi.org/10.1902/jop.2002.73.3.298.

46. Yoshihara A, Seida Y, Hanada N, Miyazaki H. A longitudinal study of the relationship between periodontal disease and bone mineral density in community-dwelling older adults. J Clin Periodontol. 2004 Aug;31(8):680-4. Available from: http://dx.doi.org/10.1111/j.1600051x.2004.00548.x.

47. Ana Pejcic, Draginja Kojovic, Ivana Grigorov, Bojana Stamenkovic. Periodontitis and osteoporosis. Medicine and Biology 2005;12:100-103.

48. Wactawski-Wende J. Periodontal Diseases and Osteoporosis: Association and Mechanisms. Annals of Periodontology. 2001 Dec;6(1):197-208. Available from: http://dx.doi.org/10.1902/annals.2001.6.1.197.

49. Nishida M, Grossi SG, Dunford RG, Ho AW, Trevisan M, Genco RJ. Calcium and the Risk For Periodontal Disease. Journal of Periodontology. 2000 Jul;71(7):1057-66. Available from: http://dx.doi.org/10.1902/jop.2000.71.7.1057.

50. Spohn G, Schwarz K, Maurer P, Illges H, Rajasekaran $\mathrm{N}$, Choi $\mathrm{Y}$, et al. Protection against Osteoporosis by Active Immunization with TRANCE/RANKL Displayed on Virus-Like Particles. The Journal of Immunology. 2005 Oct 19;175(9):6211-8. Available from: http://dx.doi.org/10.4049/jimmunol.175.9.6211. 